\title{
Disentangling language from ethnic preferences in the recruitment of domestic workers: a discrete choice experiment
}

Tobias Theys, Stef Adriaenssens, Dieter Verhaest, Nick Deschacht, Sandra Rousseau 


\begin{abstract}
The literature on service encounters rarely disentangles linguistic preferences from their association with customers' ethnic preferences, and rarely studies the selection of the service provider. We analyse the choice of domestic workers in the Brussels urban region, a region characterized by a high degree of ethnic and linguistic heterogeneity. A discrete choice experiment disentangles the linguistic from the ethnic preferences of households with respect to the recruitment of domestic workers before the encounter takes place. Our results show that households attach substantial value to linguistic convergence: they strongly prefer a housekeeper that speaks their home language, while alternative common languages are still preferred over no communication at all. Furthermore, after taking into account linguistic preferences, households still exhibit discriminatory tastes, with clear-cut ethnic preferences. The particular strength of the linguistic preferences is most likely due to the fact that domestic service encounters are recurrent and occur in the personal sphere.
\end{abstract}

\title{
Keywords
}

Service, language, ethnicity, choice experiment, domestic workers, discrimination 


\section{Introduction}

In a globalized and increasingly multilingual society (Aronin and Singleton 2008), languages, both as communicative and signalling devices, are key. In the economics and business literature, scholars have studied language in the context of employment (Chiswick and Miller 1995), and, to a lesser extent, in service contexts (Holmqvist and Grönroos 2012). Language use and linguistic skills affect labour market opportunities and customer experiences. One of the factors that can complicate research on language as a form of human capital, is the difficulty of detaching it from dimensions of ethnicity and identity. Sometimes language is the distinguishing feature defining people's ethnic belonging. Just as ethnicity can act as a signalling device for language skills (Guryan and Charles 2013), a reverse mechanism can exist where customers and employers communicate their dislike of out-groups or partiality in favour of the in-group through language.

Language use is often analysed using speech accommodation theory (Giles 1973): individuals adapt their speech to accommodate themselves to their interlocutor, in order to improve the interlocutor's evaluation of the interaction (Gallois et al. 2005). The intellectual roots of this theory lie in similarity-attraction theory (Byrne 1971), which states that increased similarity leads to increased attraction, and in social identity theory (Tajfel 1974), which states that identification with a group entails an emotional value. This sense of belonging then impacts the way individuals interact with people from other groups. Visible markers of ethnic belonging, but also language use, can be important drivers of group identification (Baumann 2004). The difference is that speech accommodation can bridge linguistic group divides, while this dynamic is often absent in the case of other ethnic boundaries. This means that language use and skills are forms of both human capital and ethnic identification, while some other features solely reflect the latter. In the remainder of this contribution, we identify these other markers as 'ethnicity'.

In service transactions, ethnic and linguistic divides can have important ramifications for the selection, quality and success of the interaction, but only rarely are both aspects taken into account simultaneously. In the limited literature on language in service encounters, it is usually only indirectly acknowledged by linking language to underlying identities (Holmqvist 2011), rather than actually disentangling ethnicity from language.

This paper studies domestic services in the Brussels urban region (Belgium), an area that is characterized by a high level of heterogeneity regarding ethnicity and language. Using a discrete choice experiment, we disentangle and analyse the ethnic and linguistic preferences of customers in the pre-core service encounter phase, where any strong preferences could carry important ramifications regarding the choice to engage the service provider. 
We contribute to the literature on language and ethnicity in service transactions in three important ways. First, a discrete choice experiment is a novel and especially suitable methodology for analysing and disentangling the roles of language and ethnicity. This explicit separation is important, since they can be expected to correlate. It therefore is methodologically difficult to detach language from ethnicity in observational studies (Reyes 2010). Our method of data collection, selecting random households that have sufficient interest in hiring a domestic worker, ensures the external validity of our experiment. Furthermore, by implying ethnicity through names, we reduce potential social desirability bias. To the best of our knowledge, only one other study has already experimentally disentangled ethnic from language preferences in service encounters. By analysing the impact of ethnic similarity and the use of primary or secondary language on the perception of service recovery in a restaurant environment, Azab \& Clark (2017) found that ethnic similarity and language convergence depend on whether the customer is part of the majority population. However, in the phase after the service encounter has taken place, the ramifications of ethnic or linguistic discrimination could be less direct, compared to the pre-core service encounter phase, where the decision to go ahead with the encounter is taken.

Second, our setting differs in at least two ways from earlier research. In our setting, encounters between the service provider and the customer are ongoing, and take place in the personal, even intimate sphere of the customer. This implies frequent direct contact, and a certain degree of trust therefore is paramount. Meanwhile, a one-off service encounter, for instance in a restaurant, requires only limited involvement from the customer, and a 'weak tie' between the provider and the customer. As argued by Holmqvist \& Van Vaerenbergh (2013), this limited involvement could lower the importance of being served in the native language. A similar dynamic may be expected to occur regarding ethnicity: in an environment that requires frequent interaction, ethnic convergence may be considered more important.

Third, Voorhees et al (2017) note the pre-core service encounter period has generally received less attention from researchers, despite its importance. This gap in the literature is corroborated by Holmqvist, Van Vaerenbergh, \& Grönroos (2017) in their overview of the literature on language in the service encounter, stating that there is only limited research on the role of language before the service encounter takes place, and no research at all about the impact of language mismatch on the decision to go ahead with the service encounter. By focussing on the decision to hire the services of a domestic worker with specific language skills, we address this gap directly.

The results of our paper have both managerial and policymaking relevance. After distinguishing the impact of language from ethnicity, our results show that the dislike for domestic workers with certain backgrounds is rooted 
in a combination of discrimination and language barriers, where the importance of linguistic convergence is especially important. A focus on improving the language skills of workers can therefore be a valuable investment for companies and government alike, since it could give access to a broader service market and the average customer is willing to pay a surcharge for a domestic worker with the desired language skills. Moreover, it allows one to reduce discriminatory recruitment practices without having to worry too much about potentially adverse customer reactions.

The remainder is organized as follows. Section 2 presents the literature on language skills and its relation to ethnicity, the specifics of domestic work, and sets out a number of hypotheses. Section 3 introduces the data, while the fourth outlines our experiment. Section 5 presents and discusses the results and the sixth section concludes.

\section{Literature}

\subsection{Language and ethnicity in service transactions}

Overall, studies show that language proficiency has a positive influence on labour market performance, as measured in earnings and employment opportunities (Berman et al. 2003; Dustmann and Fabbri 2003; Chiswick and Miller 2010). However, this literature has inherent limitations. First, many studies focus on migrants in countries with one dominant vehicular language, or on the specific case of bilinguals. Second, there are endogeneity issues (Chiswick and Miller 1995): language skills may directly depend on motivation, unmeasured ability and the time that the subject has been in the country. Third, part of the impact of language skills on earnings may be mediated by education (Bleakley and Chin 2004).

Recent changes in sectorial labour demand probably have an impact on the importance of language skills. In particular, the rise of the demand for (low-skilled) workers in the service sector (Autor and Dorn 2013), where direct contact with customers occurs frequently, should increase the importance of language skills. While the process of a service encounter has been extensively studied (Bitner 1990; Grönroos 2008), the impact of a linguistic mismatch between consumer and service provider has received (too) little attention (Marcella and Davies 2004; Holmqvist 2011). Some scholars have called for and initiated research to fill this gap, focusing on the role of this linguistic (mis)match (Van Vaerenbergh and Holmqvist 2014; Alvarez et al. 2017; Bell and Puzakova 2017). Generally, both correlational and experimental designs find an important role for language (mis)match in service encounters, where factors such as the involvement, perceived control and language skills 
can impact its importance. Language convergence is not always preferred: in some settings, language divergence is explicitly part of the service setting, adding to the consumer's experience of the service and its authenticity (Kraak and Holmqvist 2017). Also, consumers who initiate interaction in a language which is not their first language, seem to prefer that the service provider accommodates to the language they choose to interact in (Holmqvist et al. 2019). Despite the recent upsurge in attention, there are still important gaps: in a recent literature overview, Holmqvist et al. (2017) conclude that, to date, there is no research that looks at the role of language in a customer's decision to engage with the provider, as proposed by Holmqvist \& Grönroos (2012).

In service interactions, language plays a double role. On a practical level, language is a form of human capital. As such it is a key vehicle in allowing the exchange of information between the parties. This exchange facilitates coordination by reducing its cost, and it can greatly improve the quality of the outcome (Bitner et al. 1997). If this is perceived as such by consumers, they might prefer linguistic convergence. Outside the purely instrumental use of languages as a communication device, language also plays a role at the level of identity. From this dimension of perceived group membership, language has a different kind of impact on how consumers and service providers evaluate each other. In this context, the speech accommodation theory (Giles 1973) states that speech convergence occurs when one party adapts their speech to become more similar to their interlocutor, often in order to be perceived more positively by the interlocutor. Speech accommodation theory builds on social identity theory (Tajfel and Turner 1979). Social identity is defined as the belief that one belongs to a certain group, combined with a level of affective attachment to the group (compare Haslam et al. 2012). Overall, this kind of belonging is expected to increase the value attached to members of the in-group, resulting in in-group favouritism (Tajfel 1974), as confirmed by a recent meta-analysis (Balliet et al. 2014). While group identification can be based on a wide range of characteristics, language and ethnicity are two prime examples. Another relevant theoretical frame is the so-called "similarity-attraction effect", which shows among other things that attraction is stronger to those individuals with whom we can interact easily or comfortably (Montoya et al. 2008). Although intrinsically correlated, the implications are quite different: speech accommodation can bridge a language schism between groups. Such a mechanism does not exist for other ethnic properties, such as people's name or distinguishable features. We define the latter as 'ethnicity', and distinguish it from language skills. Since the potential measures to be taken depend directly on the type of identification, it is important to distinguish between the two.

A second reason why ethnic and linguistic considerations should both be taken into account is the risk that either could be used as a signalling device for the other, in the event that only one of the two is considered. In a market with imperfect information, employers and consumers are known to use certain observable characteristics as 
signalling devices for unknown characteristics. Often, ethnicity takes the role of the signalling device (Guryan and Charles 2013), for example in the extensive experimental literature on call-backs to job applications (Bertrand and Mullainathan 2004; Baert et al. 2015).

Attempting to detach language from ethnicity empirically is notoriously hard, especially in observational studies (Reyes 2010). Perhaps the earlier lack of attention to language in service encounters can be partly attributed to these methodological challenges. Given these challenges, this literature often assumes that language preferences are inherently tied to an underlying identity or ethnic belonging. Azab \& Clark (2017) do detach language from ethnicity in an experimental paper on service recovery in the US. They use an experimental design to analyse the impact of language (primary or secondary) and ethnicity (similar or dissimilar) on the satisfaction of customers regarding recovery after a service failure. They find that language matching can have an important impact for the majority population, but not for the minority population, and that ethnic similarity only plays a role for the minority population.

\subsection{The domestic work industry}

The tendencies that characterize linguistic and ethnic preferences in service encounters may be even stronger in domestic work. In Europe, migrant women make up the majority of the total population of domestic workers (Gallotti 2009). Ethnic diversity in domestic services has already been studied extensively (Gaitskell et al. 1983; Bakan and Stasiulis 1995; Bott 2005; Anderson 2007). Notwithstanding the weaker bargaining position of migrant domestics (Palenga-Möllenbeck 2013), many consumers steer clear of certain groups because of ethnic stereotypes that they link to a certain country of origin (Abrantes 2014); Han, 1989). This creates a difficult situation for matching agencies, which are pressured to discriminate, although they are legally not permitted to discriminate (Bakan and Stasiulis 1995).

Despite the diversity of the workforce, research on the role of language and language disparity in domestic work is lacking. In a study of Polish construction workers and cleaners in Belgium, Goddeeris (2008) notes the high intensity of contact between cleaners and consumers, even when they do not speak the same language. Kwan \& Dunworth (2016) find that, for Philippine domestics in Hong Kong, a functional level of English (the usual vehicular language between consumer and domestic worker) is a criterion in the hiring process. 


\subsection{Hypotheses}

Based on the intricacies of language and ethnicity in service transactions, the importance of disentangling the two, and the direct interaction that domestic workers have with the home environment of consumers, we develop hypotheses concerning the role of language and ethnicity in the context of a domestic service transaction. It should be clear that these hypotheses are not directly derived from the discussed theoretical framework, but that the latter do ascertain that language use as a communicative device differs conceptually and empirically from language as a tool for discrimination.

First, in line with social identity theory and the similarity-attraction mechanism, we expect consumers to prefer service providers with the same ethnicity. Given the recurring character and the personal nature of the encounters, we expect this preference to matter in particular in the context of domestic workers.

H1. Consumers prefer ethnic similarity in their choice of a domestic worker.

Second, we also expect a preference for domestic workers from the own linguistic group. As opposed to the preference for ethnic similarity, the preference for linguistic similarity can exist both as a signal of group membership, and because consumers want to ensure clear communication that will improve coordination in the service transaction.

H2. Consumers prefer linguistic similarity in their choice of a domestic worker.

Third, at the identity level, one may expect consumers to take into account not just whether domestic workers belong to the same group, but also the overall distance from other groups. This primarily results in a preference for more adjacent ethnic groups.

H3. Consumers prefer domestic workers from adjacent ethnic groups over more distant ethnic groups.

Fourth, we expect that consumers prefer languages they are (somewhat) familiar with over no communication. This also makes sense on the practical level, as communication in a familiar language can still improve the quality of the coordination, as compared to no verbal communication at all.

H4. Consumers prefer domestic workers from adjacent linguistic groups over more distant linguistic groups.

Finally, consumers who are also proficient in languages different from their native one could be more willing and able to switch towards these linguistic groups. These consumers will therefore be more inclined to select housekeepers with these language skills. 
H5. The preference for adjacent linguistic groups is moderated by the language skills of the consumer.

\section{Data}

We focus on domestic workers in the Brussels urban area. The region is highly heterogeneous regarding language: in the inner region (the Brussels-Capital Region), French is the vehicular language, while it is Dutch in the periphery. Furthermore, knowledge of English is common, given the highly internationalised environment. This multilingual setting allows us to distinguish several layers of linguistic preferences. Ethnically, the area is no less diverse: in 2016, 56\% of the Brussels-Capital Region population was born in a different country (Hermia and Sierens 2017).

Data collection took place in sampled areas and consisted of two survey waves, preceded by a pilot study. Because language use differs strongly between the inner and outer region, we decided to select two equal samples. Sampling was organized in two stages. In the first stage, 25 statistical units (the smallest geographical unit) were selected in both the inner and outer region, based on a probability proportional to the average income in the unit, as this is a strong predictor of outsourcing domestic work (Marx and Vandelannoote 2015).

The second stage of the sampling was random. Starting from the randomly attributed starting address, fieldworkers interviewed every fourth household within the unit. Door-to-door interviews were conducted in the pilot study (April-June 2015) and the first survey wave (April-May 2016). The second survey wave (start of 2017) was a postal survey in statistical units that were not covered by fieldworkers during the earlier waves. Starting from a random starting address, every third household received an envelope containing the survey, including the possibility of filling in the survey online.

Respondents filled in a questionnaire of three parts, in French or Dutch. The first part gauged socio-demographic information, the second part contained the choice experiment, and the third part was reserved for respondents employing a domestic worker. To ensure the accuracy of the choice experiment and its external validity, respondents were asked to participate in the choice experiment only if they had experience with buying domestic work services, or if they reported sufficient interest in doing so in the near future. The subjects were first introduced to the choice experiment. To reduce the impact of social desirability in the face-to-face interviewing situation (first wave), participants were asked to choose the profiles on the tablet used for the survey without any help or interference from the interviewer. 
The pilot was used to improve the design of the choice experiment. In the first and second wave, 122 and 257 respondents (of which 63 online) respectively participated in the choice experiment, resulting in 379 participants. Given our focus on language, we retain those subjects that declare they speak the language of the survey (Dutch or French) at home $(n=343)$. Table 1 summarizes the main characteristics of the sample.

Table 1. Respondents' characteristics

\begin{tabular}{lc}
\hline & Full sample (N=343) \\
\hline \hline Age (average) & 58.3 \\
Female (\%) & 62.5 \\
Household income (median) & Between $€ 2790$ and $€ 3360$ \\
High skilled (\%) & 77.8 \\
Low skilled (\%) & 4.4 \\
Outer region (\%) & 56.3 \\
Native Dutch language respondents (\%) & 32.7 \\
Ability to converse in non-native country language (\%) & 72.6 \\
Ability to converse in English (\%) & 70.0 \\
Currently employs a housekeeper (\%) & 73.4 \\
\hline
\end{tabular}

Just over two-thirds responded in French. Almost three out of four can have a conversation in the non-native country language (so either Dutch or French), while 70\% reports to be able to converse in English. Nearly three out of four currently employ a housekeeper.

\section{Methodological framework}

\subsection{Discrete choice experiments}

Discrete choice experiments (DCEs) ask subjects to choose between different options for a good, service, or, in our case, a person delivering a service. Each option under consideration is described by a number of characteristics (so-called 'attributes'), which can have different categories or ordered levels (so-called 'levels') (Hanley et al. 2001). Usually, an opt-out scenario is included, choosing none of the offered options. This option assures that the subject only chooses an option if (s)he likes it, which prevents biased estimates(Haaijer et al. 2001). The set-up regarding the attributes and levels to include are based on literature regarding domestic work, considerations of involved scholars and the insights learned from the pilot wave.

Discrete choice experiments have become a popular method for analysing situations where revealed preferences are not available or hard to measure, or where the commodity is not yet on the market. They have been used to 
measure the impact of language and ethnicity in an electoral context in the US (Lavariega Monforti et al. 2013) and Ukraine (Frye 2015). A DCE is useful for our case, since there is no existing (legal) market where consumers can freely compile their preferred profile. Moreover, this method allows us to explicitly take into account the correlation between language proficiency and ethnicity, and to investigate the effects of both separately.

The analysis of choices is based on random utility theory: the respondent chooses the alternative that delivers the highest utility. The workhorse model to analyse these choices is the conditional logit, which models utility based on the attributes of the alternatives under consideration (McFadden 1973). While this model is easy to use, it assumes homogenous preferences among respondents. To address this limitation, we estimate a mixed logit model, which allows subjects to have heterogeneous preferences with regard to their choices. To estimate the parameters, we use a simulated maximum likelihood estimator with 500 Halton draws for each estimated model (Hole 2007).

In addition to the attribute levels, we add an alternative-specific constant (ASC) for each profile. A significant positive coefficient means the respondent sees added utility in choosing one of the profiles over the opt-out option. The ASCs also capture the effects of unobserved characteristics and the impact of the reference level of the dummy variables used in the estimation.

\subsection{Attributes and levels}

The profiles of housekeepers in our choice experiment differ in five respects: language, ethnicity, age, employment status and price (table 2). Since our focus is on the initial decision to buy domestic services delivered by a worker with a specific socio-demographic profile, we choose not to vary profiles in terms of performancerelated attributes such as speed and quality of work and to only present female candidates. Given the subject of this paper, we will only discuss the attributes language, ethnicity and price. The attributes age and employment status (formal/informal) act as control variables, with the latter one being part of a different study on the persistence of informal work (Adriaenssens et al. Submitted), with a different sample and methodology. The price of the service ranges from cheaper $(€ 4)$ to more expensive $(€ 15)$ than the current price on the labour market: a service voucher buying one hour of legal domestic work costs $€ 9$, of which a part is tax-deductible. 
Table 2. Overview of attributes and levels

\begin{tabular}{ll}
\hline Attributes & Attribute levels \\
\hline \hline 1. Price & 1. $€ 4$ \\
& $2 . € 6$ \\
& $3 . € 9$ \\
& $4 . € 12$ \\
& $5 . € 15$ \\
& 1. Flemish \\
2. Name & 2. Walloon \\
& 3. Maghreb \\
& 4. Polish \\
& 1. Native language \\
3. Language & 2. Non-native country language \\
& 3. English \\
& 4. Neither Dutch, French or English \\
& 1. Direct payment \\
4. Employment status & 2. Service voucher with tax deduction \\
& 3. Service vouchers without tax deduction \\
& 1. 20 \\
5. Age & 2. 35 \\
& 3. 55 \\
\hline
\end{tabular}

The particular attribute 'language' has four levels. The first level, used as a base level when analysing the results, is the vehicular language the respondent chooses, i.e. the language of the survey (Dutch or French). The second level is the other, non-native country language. The third level is English, while the fourth level is no knowledge of Dutch, French or English.

As mentioned earlier, without sharing any information on ethnicity, the mastered language could serve as a signalling device. To disentangle language from explicit ethnic effects, we add information on ethnic ancestry through an extra attribute with four levels: Flemish and Walloon, which signal native ancestry, and Polish or Maghreb. Maghreb ethnicity is chosen because of its dominance amongst migrants from outside of the EU: in the Brussels-Capital Region, $30.8 \%$ of the population with a non-EU nationality has a Maghreb background (Noppe et al. 2018). We focus on a Polish ancestry, rather than on a more general Eastern-European ancestry, because Polish workers form a considerable part of the workforce in the domestic work industry: in $2016,31.1 \%$ of the domestic workers in the Brussels-Capital Region had Polish nationality, compared to only 26.1\% with a Belgian nationality (Schooreel and Valsamis 2017). 
The ethnicity attribute is added to the choice profile by using a name that is linked to the ethnicity. To minimize social desirability bias, the name of the housekeeper, which was put at the top of every choice card, was not explicitly represented as an attribute. We tested rigorously whether the chosen names are in fact linked to these ethnicities by respondents. Initially, to establish a list of names that act as proxies for the four ethnicities, we chose names with an ethnic dimension (at face value) from a list of common names in Belgium. This list was then randomly ordered and presented to a group of subjects, asking them to link the name to a nationality. We retained those names that were consistently linked by subjects to the nationalities proposed in the setup.

Using the levels of the attributes, a large number of unique profiles can be constructed. We used the Ngene software (ChoiceMetrics 2014) to reduce the number of choice sets presented to respondents. This resulted in a D-efficient fractional factorial design, which generally produces better results when compared to the traditional orthogonal design and requires a smaller sample size (Rose et al. 2008). Our design contains 24 choice cards, organized in three blocks, so every respondent was asked to make a choice from eight choice cards, each containing two profiles and an opt-out option.

To improve efficiency, prior information about the attributes was used. Based on the results of the pilot study 'best guesses' were assigned to the mean values of the parameters. With the help of these fixed priors, a design was generated with a sufficiently low $\mathrm{D}_{\mathrm{p}}$-error ( $\mathrm{p}$ from priors), a measure of the inefficiency of the model (Hensher et al. 2015). The design of this experiment resulted in a $D_{p}$-error of 1.4.

\section{Results}

The preferences of the sample are presented in table 3. The base profile in this case is a Flemish housekeeper that speaks the native language of the respondent.

The coefficients of the alternative-specific constants (ASCs), positive and statistically significant, show that subjects demonstrate a willingness to hire the services of one of the offered profiles instead of opting out (the optout was selected for $34.06 \%$ of the choice cards). The price has a statistically significant negative coefficient: all else being equal, respondents prefer a less expensive option.

Our two main subjects of interest, ethnicity and language, show that subjects do not differentiate between hiring local ethnicities (Flemish and Walloon) and a Polish ethnicity. However, the results are different for Maghreb profiles, where subjects show a clear dislike, compared to the three alternatives (additional Wald-test statistics reveal all comparisons to be significant at the $0.1 \%$-level; see appendix A). The difference in preferences for a 
Polish or a Maghreb profile is noteworthy, but not necessarily surprising. Recent reviews and meta-analyses have shown that individuals with a Maghreb background are often particularly discriminated against. Zschirnt \& Ruedin (2016) show that in experiments in hiring decisions, the difference between call-backs for applicants from the majority and minority differs most strongly for Arab and Middle-Eastern applicants. Distinct stereotypes and country images could play a role, where Maghreb individuals are perceived more negatively than Polish individuals, as suggested by a survey on discrimination (Thiebaut et al. 2009). While these results are only partly in line with hypothesis 1 , as native ethnicity is not preferred over Polish ethnicity, they confirm hypothesis 3 , assuming a Polish ethnicity is considered more close compared to a Maghreb ethnicity. It is also notable that there is significant heterogeneity in the preferences regarding ethnicities: evidently, subjects differ substantially regarding the importance of ethnic background.

Table 3. Estimation results of the mixed logit model

\begin{tabular}{|c|c|c|c|c|}
\hline & \multicolumn{2}{|c|}{ Mean } & \multicolumn{2}{|c|}{ Standard deviations } \\
\hline & Coefficients & $\begin{array}{c}\text { Standard } \\
\text { errors }\end{array}$ & Coefficients & Standard errors \\
\hline$\underline{\text { Price }}$ & $-0.204 * * *$ & 0.018 & & \\
\hline Alternative specific constant 1 & $4.564 * * *$ & 0.249 & & \\
\hline Alternative specific constant 2 & $4.665 * * *$ & 0.259 & & \\
\hline \multicolumn{5}{|l|}{ Ethnicity (ref.: Flemish) } \\
\hline Maghreb & $-0.794 * * *$ & 0.161 & $1.130 * * *$ & 0.187 \\
\hline Polish & 0.063 & 0.182 & $1.435 * * *$ & 0.173 \\
\hline Walloon & -0.126 & 0.186 & $1.075 * * *$ & 0.241 \\
\hline \multicolumn{5}{|l|}{$\frac{\text { Language (ref.: native }}{\text { language) }}$} \\
\hline Non-native country language & $-1.762 * * *$ & 0.147 & $0.553 *$ & 0.240 \\
\hline English & $-1.645 * * *$ & 0.186 & $1.141 * * *$ & 0.246 \\
\hline No communication & $-4.068 * * *$ & 0.257 & 0.015 & 0.699 \\
\hline \multicolumn{5}{|l|}{$\begin{array}{l}\text { Contract status (ref.: service } \\
\text { voucher with tax deduction) }\end{array}$} \\
\hline Informal employment & $-2.738 * * *$ & 0.201 & $2.046^{* * *}$ & 0.195 \\
\hline $\begin{array}{l}\text { Service voucher without tax } \\
\text { deduction }\end{array}$ & $-1.411 * * *$ & 0.154 & $1.008 * * *$ & 0.197 \\
\hline \multicolumn{5}{|l|}{ Age (ref.: 35) } \\
\hline Age $=20$ & $-0.855^{* * *}$ & 0.138 & $1.013 * * *$ & 0.195 \\
\hline Age $=55$ & $-0.560 * * *$ & 0.141 & $0.676^{* *}$ & 0.230 \\
\hline Log-likelihood & \multicolumn{4}{|c|}{-1980.233} \\
\hline
\end{tabular}


The coefficients for the levels of the language attribute confirm our second hypothesis: respondents significantly favour being served by a housekeeper that speaks their native language. Second, subjects prefer both the nonnative country language and English over a candidate that speaks none of the languages (p-values $<0.001$; see appendix A), indicating a preference for services in the non-native country language frequently spoken in the region. Furthermore, respondents reveal homogeneous preferences in their dislike of not being able to communicate: subjects seem to agree that at least some method of communication is important. These results confirm hypothesis 4 .

The preference for the non-native country language and English over no communication is partly driven by the high share of respondents that feel able to have a conversation in these languages, as stated in hypothesis 5: an interaction effect between the knowledge of the two languages and the preference for these languages (table 4), shows that knowledge of the alternative languages lowers the dislike, although the native language is still preferred (p-values $<0.001$, see appendix A); even respondents without a knowledge of English or the non-native country language still prefer them over no communication ( $\mathrm{p}$-values $<0.001$; see appendix A). In both models, there is a degree of heterogeneity regarding the preference for being served in the non-native country language or English.

Table 4. Estimation results of the mixed logit model, language skill interactions included

\section{Coefficients}

\section{Language (ref.: native language)}

Non-native country language

English

No communication

\section{Interaction effects}

Non-native country language * non-native country langue skills $\quad 1.153 * * *$

English * English language skills

Notes: Selected coefficients. Significant coefficients are indicated by * $(p<0.05), *^{*}(p<0.01)$ and $* * *$ $(p<0.001)$. No communication $=$ no knowledge of Dutch, French or English. Apart from the added interaction terms, the specification is the same as in Table 3; full estimation results are available upon request.

To obtain more tangible values, we can calculate the willingness-to-pay (WTP) for marginal changes in attributes by dividing the coefficient of the level by the coefficient of price, although stated preference methods carry the inherent risk of hypothetical bias: respondents often overestimate their willingness-to-pay compared to real-life situations (Ready et al. 2010). However, the relative importance of attributes and attribute levels is considered less distorted, allowing us an easier comparison between attributes and levels. The results in table 5 further 
establish the importance of the language attribute, where subjects are willing to pay significantly more to be served in the language they prefer than for the preferred level of the ethnicity attribute. Avoiding being served by a housekeeper with no communication skills is prominently prioritized.

Table 5. Subjects' willingness-to-pay for language and ethnicity characteristics

\begin{tabular}{|c|c|c|c|}
\hline & Willingness-to-pay (€) & Upper bound $(€)$ & Lower bound $(€)$ \\
\hline \multicolumn{4}{|l|}{ Ethnicity (ref.: Flemish) } \\
\hline Maghreb & -3.89 & -5.65 & -2.13 \\
\hline Polish & 0.31 & -1.43 & 2.05 \\
\hline Walloon & -0.62 & -2.43 & 1.20 \\
\hline \multicolumn{4}{|c|}{ Language (ref.: native language) } \\
\hline Non-native country language & -8.63 & -10.67 & -6.58 \\
\hline English & -8.05 & -10.26 & -5.85 \\
\hline No communication & -19.92 & -23.78 & -16.06 \\
\hline
\end{tabular}

\section{Discussion and conclusion}

In this paper, we conduct a discrete choice experiment in an urban region that exhibits a large linguistic and ethnic diversity, to assess the ex-ante preferences of households regarding the language and ethnicity of domestic service workers. The results allow us to draw a number of highly relevant conclusions regarding attitudes towards linguistic and ethnic divergence between consumer and service provider.

First, we find that it is important to take ethnic and linguistic preferences into account simultaneously: both characteristics are deemed important by consumers. While the results show that linguistic convergence is particularly prioritized, ethnic preferences remain significant.

Second, consumers strongly value a domestic worker who knows their native language. This result corresponds to findings in the service sector literature on the preference for being served in the native language in bilingual regions (Holmqvist 2011; Van Vaerenbergh and Holmqvist 2013) and extends this conclusion to alternative languages spoken by the service provider. Moreover, the estimated effects of language are particularly large in our study. These large effects are likely to be explained by the fact that the transaction takes place in the home environment of the customer, thereby increasing the personal involvement of the consumer and the importance of clear communication. 
Third, even if the language spoken by the domestic worker is not the native language of the consumer, the possibility of communicating with the service provider is still valued significantly. The dislike of being served by a housekeeper speaking none of the languages frequently used in the region (Dutch, French and English) is by far the most substantial. Subjects show no significant heterogeneity regarding this dislike. The dislike of the nonnative country language and English is moderated by the language skills of the subjects: subjects who are able to have a conversation in these languages, exhibit a lower level of dislike.

Fourth, in terms of ethnic preferences, on average consumers have a dislike for workers with a Maghreb background. Respondents disfavour them not only in comparison to workers with a native background, but also favour a housekeeper of Polish descent over one of Maghreb descent. The clear-cut conclusion is that discrimination remains a significant and non-trivial problem. This is even more problematic in the light of the degree of ethnic diversity in the sector of domestic work, and the ensuing high number of potential workers that are affected by this discriminatory taste of households.

Overall, these findings suggest that the language and ethnicity of the service provider will significantly impact the chance that the service encounter will take place. In an open market, the non-native country language or Maghreb ethnicity might be compensated for by a significant price reduction. However, ethnic discrimination is not allowed by law and the current Belgian system for subsidized domestic work also prevents price differentiation based on language skills; it is therefore reasonable to assume that a number of consumers drop out of the market if they are confronted with a situation in which the offered housekeeper does not have the preferred characteristics. Also, it might deter service providers to hire applicants with features that are less in demand, due to ethnic discriminatory tastes or linguistic expectations. While discriminatory tastes can only be tackled in the long term through taste changes, linguistic skills can be stimulated through a targeted educational policy.

\subsection{Managerial implications}

Our results indicate that providers that are aware of consumers' preferences in the pre-core service interaction, may successfully impact their decision to employ a domestic. The subjects in our choice experiment show clearcut ethnic and linguistic preferences. The latter are particularly substantial. In a sense, this is good news. Employers can do little to change discriminatory tastes in the short term. However, they are able to take action regarding employees' language skills. A focus on improving the language skills of domestic workers, and service providers in general, can be a socially sustainable and cost-effective investment, resulting in extra revenues through two channels. First, our experiment shows an unfulfilled demand in the market: about one fourth of the 
respondents did not employ a housekeeper at the time of the experiment, while their choices reveal an overall willingness to hire one of the offered profiles over opting out. They may back out of the service transaction because of a perceived shortage of the desired language skills; improving the degree of linguistic convergence could broaden the market of customers. Second, the results show that the average consumer is even prepared to pay a surcharge for a service provider with the desired language skills, especially for the consumer's native language.

The importance of language can also induce location-specific effects; given the lack of workers in the periphery and the abundant supply of French-speaking job seekers in Brussels, there could be room to work together with employment agencies to provide intensive language courses to jobseekers. This idea has already been partially implemented: the Brussels' employment agency has recently focused on promoting language courses for jobseekers, and a special fund subsidizes service voucher companies for their investment in language courses for employees.

\subsection{Limitations and further research}

First, our paper studies a specific sector in one region; while this is a strength of this contribution, it is also a limitation. Further research could test whether the results can be generalized to other industries within the service sector or other regions with a different linguistic or ethnic environment. Second, we did not observe directly whether some consumers actually drop out of the market because of a lack of profiles with the preferred characteristics, as implied by the results for the language and ethnicity attributes. Further research should address this question. Third, the setup of our experiment was not designed to analyse any interactions between ethnicity and language ${ }^{1}$. These could yield interesting conclusions. Finally, while our setup allows us to infer conclusions about specific ethnic population groups, we did not measure the underlying stereotypes behind these effects. Identifying the impact of these stereotypes could complement the findings of this study.

\footnotetext{
${ }^{1}$ For exploratory purposes, we did run a model with interactions between language and ethnicity levels. This model provided no additional insights.
} 


\section{References}

Abrantes Manuel. 'I Know It Sounds Nasty and Stereotyped': Searching for the Competent Domestic Worker. Gender, Work \& Organization 2014; 21 (5): 427-442.

Adriaenssens Stef, Theys Tobias, Verhaest Dieter, Deschacht Nick. Subsidized household services and informal employment: The Belgian service voucher policy. Journal of Social Policy Submitted.

Alvarez Cecilia M. O., Taylor Kimberly A., Gomez Carolina. The effects of Hispanic bilinguals language use and stereotype activation on negotiations outcomes. Journal of Business Research 2017; 72: 158-167.

Anderson Bridget. A very private business: exploring the demand for migrant domestic workers. European Journal of Women's Studies 2007; 14 (3): 247-264.

Aronin Larissa, Singleton David. Multilingualism as a new linguistic dispensation. International Journal of Multilingualism 2008; 5 (1): 1-16.

Autor David H. , Dorn David. The growth of low-skill service jobs and the polarization of the US labor market. American Economic Review 2013; 103 (5): 1553-1597.

Azab Carol, Clark Terry. Speak my language or look like me? - Language and ethnicity in bilingual customer service recovery. Journal of Business Research 2017; 72: 57-68.

Baert Stijn, Cockx Bart, Gheyle Niels, Vandamme Cora. Is there less discrimination in occupations where recruitment Is difficult? ILR Review 2015; 68 (3): 467-500.

Bakan Abigail B., Stasiulis Daiva K. Making the match: Domestic placement agencies and the racialization of women's household work. Signs: Journal of Women in Culture and Society 1995; 20 (2): 303-335.

Balliet Daniel, Wu Junhui, De Dreu Carsten K. W. Ingroup favoritism in cooperation: A meta-analysis. Psychological Bulletin 2014; 140 (6): 1556-1581.

Baumann Timothy Defining ethnicity. SAA archaeological record 2004; 4 (4): 12-14.

Bell Monique L., Puzakova Marina. ¿Y Usted? Social influence effects on consumers' service language preferences. Journal of Business Research 2017; 72: 168-177.

Berman E., Lang K., Siniver E. Language-skill complementarity: returns to immigrant language acquisition. Labour Economics 2003; 10 (3): 265-290.

Bertrand Marianne, Mullainathan Sendhil. Are Emily and Greg more employable than Lakisha and Jamal? A field experiment on labor market discrimination. American Economic Review 2004; 94 (4): 991-1013.

Bitner Mary Jo. Evaluating service encounters: The effects of physical surroundings and employee responses. Journal of Marketing 1990; 54 (2): 69-82.

Bitner Mary Jo, Faranda William T., Hubbert Amy R., Zeithaml Valarie A. Customer contributions and roles in service delivery. International Journal of Service Industry Management 1997; 8 (3): 193-205.

Bleakley H., Chin A. Language skills and earnings: evidence from childhood immigrants. Review of Economics and Statistics 2004; 86 (2): 481-496.

Bott Esther. Too close for comfort? 'Race' and the management of proximity, guilt and other anxieties in paid domestic labour. Sociological Research Online 2005; 10 (3).

Byrne Donn. The attraction paradigm. New York: Academic press, 1971.

Chiswick B., Miller P. Occupational language requirements and the value of English in the US labor market. J Popul Econ 2010; 23.

Chiswick Barry R., Miller Paul W. . The endogeneity between language and earnings: international analyses. Journal of Labor Economics 1995; 13 (2): 246-288.

ChoiceMetrics. Ngene 1.1.2 User Manual \& Reference Guide. Australia, 2014.

Dustmann Christian, Fabbri Francesca. Language proficiency and labour market performance of immigrants in the UK. Economic Journal 2003; 113 (489): 695-717.

Frye Timothy. What do voters in Ukraine want?: A survey experiment on candidate ethnicity, language, and policy orientation. Problems of Post-Communism 2015; 62 (5): 247-257.

Gaitskell Deborah, Kimble Judy, Maconachie Moira, Unterhalter Elaine. Class, race and gender: domestic workers in South Africa. Review of African Political Economy 1983; 10 (27-28): 86-108.

Gallois Cindy, Ogay Tanya, Giles Howard. Communication Accomodation Theory: a look back and a look ahead. In: William B. Gudykunst editor. Theorizing about intercultural communication. Thousand Oaks: Sage, 2005. pp. 121-148.

Gallotti Maria. The gender dimension of domestic work in Western Europe

Giles Howard. Accent mobility: A model and some data. Anthropological Linguistics 1973; 15 (2): 87-105.

Goddeeris Idesbald. Influences of Central European labour migrants on their Western employers. European Review 2008; 16 (4): 551-561. 
Grönroos Christian. Service logic revisited: who creates value? And who co-creates? European Business Review 2008; 20 (4): 298-314.

Guryan Jonathan, Charles Kerwin Kofi. Taste-based or statistical discrimination: the economics of discrimination returns to its roots. The Economic Journal 2013; 123 (572): F417-F432.

Haaijer Rinus, Wagner Kamakura, Wedel Michel. The 'no-choice' alternative to conjoint choice experiments. International Journal of Market Research 2001; 43 (1): 93-106.

Hanley Nick, Mourato Susana, Wright Robert E. Choice modelling approaches: A superior alternative for environmental valuation? Journal of Economic Surveys 2001; 15 (3): 435-462.

Haslam S. Alexander, Reicher Stephen D., Reynolds Katherine J. Identity, influence, and change: Rediscovering John Turner's vision for social psychology. British Journal of Social Psychology 2012; 51 (2): 201-218.

Hensher David A., Rose John M., Greene William H. Applied choice analysis: a primer. Cambridge: Cambridge University Press, 2015.

Hermia Jean-Pierre, Sierens Astrid. Belgen en vreemdelingen in het Brussels Gewest, van bij hun geboorte tot de dag van vandaag

Hole Arne Risa. Fitting mixed logit models by using maximum simulated likelihood. The Stata Journal 2007; 7 (3): $281-312$.

Holmqvist Jonas. Consumer language preferences in service encounters: a cross-cultural perspective. Managing Service Quality: An International Journal 2011; 21 (2): 178-191.

Holmqvist Jonas, Grönroos Christian. How does language matter for services? Challenges and propositions for service research. Journal of Service Research 2012; 15 (4): 430-442.

Holmqvist Jonas, Van Vaerenbergh Yves. Perceived importance of native language use in service encounters. The Service Industries Journal 2013; 33 (15-16): 1659-1671.

Holmqvist Jonas, Van Vaerenbergh Yves, Grönroos Christian. Language use in services: Recent advances and directions for future research. Journal of Business Research 2017; 72: 114-118.

Holmqvist Jonas, Van Vaerenbergh Yves, Lunardo Renaud, Dahlén Micael. The language backfire effect: how frontline employees decrease customer satisfaction through language use. Journal of Retailing 2019; 95 (2): 115-129.

Kraak Johannes Marcelus, Holmqvist Jonas. The authentic service employee: Service employees' language use for authentic service experiences. Journal of Business Research 2017; 72: 199-209.

Kwan Noel, Dunworth Katie. English as a lingua franca communication between domestic helpers and employers in Hong Kong: A study of pragmatic strategies. English for Specific Purposes 2016; 43: 13-24.

Lavariega Monforti Jessica, Michelson Melissa, Franco Annie. ¿Por Quién Votará? Experimental evidence about language, ethnicity and vote choice (among Republicans). Politics, Groups, and Identities 2013; 1 (4): 475-487.

Marcella Rita, Davies Sylvie. The use of customer language in international marketing communication in the Scottish food and drink industry. European Journal of Marketing 2004; 38 (11/12): 1382-1395.

Marx Ive, Vandelannoote Dieter. Matthew runs amok: The Belgian service voucher scheme. In: Clément Carbonnier, Nathalie Morel editors. The political economy of household services in Europe. Basingstoke: Palgrave-Macmillan, 2015. pp. 197-220.

McFadden Daniel. Conditional logit analysis of qualitative choice behavior. In: P. Zarembka editor. Frontiers in econometrics. New York: Academic Press, 1973. pp. 105-142.

Montoya R. Matthew, Horton Robert S., Kirchner Jeffrey. Is actual similarity necessary for attraction? A metaanalysis of actual and perceived similarity. Journal of Social and Personal Relationships 2008; 25 (6): 889-922.

Noppe Jo, Vanweddingen Myriam, Doyen Gerlinde, Stuyck Karen, Feys Yinthe, Buysschaert Philippe. Vlaamse Migratie- en Integratiemonitor 2018

Palenga-Möllenbeck Ewa. New maids - new butlers? Polish domestic workers in Germany and commodification of social reproductive work. Equality, Diversity and Inclusion: An International Journal 2013; 32 (6): 557-574.

Ready Richard C., Champ Patricia A., Lawton Jennifer L. Using respondent uncertainty to mitigate hypothetical bias in a stated choice experiment. Land Economics 2010; 86 (2): 363-381.

Reyes A. Language and ethnicity. In: Nancy H. Hornberger, Sandra Lee McKay editors. Sociolinguistics and language education. Bristol Multilingual Matters, 2010. pp. 398-426.

Rose John M., Bliemer Michiel C. J., Hensher David A., Collins Andrew T. Designing efficient stated choice experiments in the presence of reference alternatives. Transportation Research Part B: Methodological 2008; 42 (4): 395-406.

Schooreel Tess, Valsamis Daphné. Evaluatie van het stelsel van de dienstencheques voor buurtbanen en -diensten in het Brussels Hoofdstedelijk Gewest, 2014 en 2015

Tajfel Henri. Social identity and intergroup behaviour. Social Science Information 1974; 13 (2): 65-93. 
Tajfel Henri, Turner John C. An integrative theory of intergroup conflict. In: W. G. Austin, S. Worchel editors. The social psychology of intergroup relations Monterey, CA: Brooks/Cole, 1979. pp. 33-47.

Thiebaut J.P., Vandenbroucke S., Spaas C., Peetroons L. Survey: Hoe tolerant zijn Belgen ten opzichte van etnische minderheden

Van Vaerenbergh Yves, Holmqvist Jonas. Speak my language if you want my money. European Journal of Marketing 2013; 47 (8): 1276-1292.

Van Vaerenbergh Yves, Holmqvist Jonas. Examining the relationship between language divergence and word-ofmouth intentions. Journal of Business Research 2014; 67 (8): 1601-1608.

Voorhees Clay M., Fombelle Paul W., Gregoire Yany, Bone Sterling, Gustafsson Anders, Sousa Rui, Walkowiak Travis. Service encounters, experiences and the customer journey: Defining the field and a call to expand our lens. Journal of Business Research 2017; 79: 269-280.

Zschirnt Eva, Ruedin Didier. Ethnic discrimination in hiring decisions: a meta-analysis of correspondence tests 1990-2015. Journal of Ethnic and Migration Studies 2016; 42 (7): 1115-1134. 


\section{Appendix}

Table A.1. Results of Wald $\mathrm{Chi}^{2}$-tests testing significant differences between coefficients.

\begin{tabular}{|c|c|c|c|}
\hline & Coefficient & Wald Chi-square(1) & p-value \\
\hline \multicolumn{4}{|l|}{ Tests concerning results in table 3} \\
\hline Walloon - Maghreb $=0$ & 0.668 & 13.85 & 0.000 \\
\hline Polish - Maghreb $=0$ & 0.857 & 24.54 & 0.000 \\
\hline English - no communication $=0$ & 2.423 & 87.17 & 0.000 \\
\hline $\begin{array}{l}\text { Non-native country language - no } \\
\text { communication }=0\end{array}$ & 2.306 & 97.93 & 0.000 \\
\hline English - non-native country language $=0$ & 0.117 & 0.410 & 0.521 \\
\hline \multicolumn{4}{|l|}{ Tests concerning results in table 4} \\
\hline English main effect - no communication $=0$ & 1.544 & 17.22 & 0.000 \\
\hline $\begin{array}{l}\text { Non-native country language main effect - no } \\
\text { communication }=0\end{array}$ & 1.450 & 23.45 & 0.000 \\
\hline $\begin{array}{l}\text { English main effect }+ \text { interaction effect } \\
\text { English proficiency }=\mathbf{0}\end{array}$ & -1.306 & 43.92 & 0.000 \\
\hline $\begin{array}{l}\text { Non-native language main effect }+ \\
\text { interaction effect non-native language } \\
\text { proficiency }=0\end{array}$ & -1.466 & 93.92 & 0.000 \\
\hline $\begin{array}{l}\text { Non-native language main effect - English } \\
\text { main effect }=0\end{array}$ & 0.094 & 0.07 & 0.785 \\
\hline $\begin{array}{l}\text { Non-native language main effect }+ \\
\text { interaction effect non-native language } \\
\text { proficiency = English main effect }+ \\
\text { interaction effect English proficiency }\end{array}$ & 0.16 & 0.65 & 0.4198 \\
\hline
\end{tabular}

